\title{
The alcohol and tobacco burden of India
}

The Indian College of Physicians (ICP) of the Association of Physicians of India has recently released guidelines on the management of addictive disorders in persons with type 2 diabetes mellitus (DM) ${ }^{[1]}$ These guidelines underscore the multifaceted relationship between addictive disorders and DM. These highlights need to screen, prevent, and manage addictive disorders while minimizing the potential adverse impact of both these disorders, and their treatment, on glycemic control.

The importance given to this topic by the ICP is praiseworthy. India is home to the second largest population of persons living with DM. ${ }^{[2]}$ India also faces a huge burden of addictive disorders, including those related to alcohol, tobacco, opioids, cannabis, and other drugs such as paan (betel net). ${ }^{[3]}$

Both DM and addictive disorders receive their fair share of attention in research and policy making. However, diabetes opinion leaders have not factored in the prevalence of drug addiction into current plans for continuing medical education, research, or public health interventions.

Recently, published data from the National Family Health Survey 4 (NFHS4) ${ }^{[4]}$ provide more recent estimate of the burden of tobacco and alcohol use across India. A few points are clear from the NFHS4 results:

1. Alcohol and tobacco use is common in India

2. Alcohol and tobacco use is common among both women and men, though the prevalence is higher in males

3. There is great heterogeneity in the prevalence of alcohol and tobacco use across states
4. Alcohol and tobacco use is most prevalent in the North Eastern of India

5. Alcohol and tobacco use is least prevalent in the North Western and Western part of India.

Table 1 provides a snapshot of states where alcohol and tobacco use is most and least prevalent. Northeastern states along with Chhattisgarh and Telangana (with high tribal population) report the highest use of alcohol. On the other hand, many states report virtually nil consumption in women, with four states demonstrating a $<20 \%$ prevalence of alcohol use in men.

Tobacco use appears to be much more prevalent than alcohol use, with the northeastern states leading the list of highest tobacco users among both women and men. Women from Northwestern part of the country report the lowest use of tobacco, while men from a wide geographical spectrum (Puducherry, Punjab/Chandigarh, and Goa) are least likely to consume the same.

The NFHS 4 does not provide data on the use of other drugs, such as opioids, cannabis, and betel quid (Paan). However, the information obtained from NFHS4 offers food for thought, and for action. Professional organizations working in the field of diabetology must incorporate management of addictive disorders in their diabetes training plans. Existing recommendations to stop tobacco use, and limit alcohol use, ${ }^{[5,6]}$ must be emphasized in unambiguous terms. Diabetes care professionals across the country must be encouraged to screen, diagnose, counsel, manage, and if required, refer, persons with addictive disorders.

Table 1: States with high and low reported use of alcohol and tobacco as per National Family Health Survey 4

\begin{tabular}{|c|c|c|c|c|c|c|c|c|}
\hline & \multicolumn{4}{|c|}{ Highest reported use (\%) } & \multicolumn{4}{|c|}{ Lowest reported use (\%) } \\
\hline & States & Women & States & Men & States & Women & States & Men \\
\hline \multirow[t]{5}{*}{ Alcohol } & $\begin{array}{l}\text { Arunachal } \\
\text { Pradesh }\end{array}$ & 26.3 & $\begin{array}{l}\text { Arunachal } \\
\text { Pradesh }\end{array}$ & 59.0 & Lakshadweep & 0 & Lakshadweep & 6.8 \\
\hline & Sikkim & 23.0 & Tripura & 57.6 & $\begin{array}{l}\text { Dadra and Nagar } \\
\text { Haveli }\end{array}$ & 0 & Jammu and Kashmir & 10.5 \\
\hline & Telangana & 8.8 & Telangana & 53.9 & Haryana & 0.1 & Gujarat & 11.1 \\
\hline & Manipur & 6.1 & Chhattisgarh & 52.7 & Jammu and Kashmir & 0.1 & Rajasthan & 15.9 \\
\hline & Chhattisgarh & 5.0 & Manipur & 52.5 & Punjab & 0.1 & Maharashtra & 20.5 \\
\hline \multirow[t]{5}{*}{ Tobacco } & Mizoram & 59.2 & Mizoram & 80.4 & Punjab & 0.1 & Puducherry & 14.4 \\
\hline & Manipur & 48.8 & Meghalaya & 72.2 & Chandigarh & 0.4 & Punjab & 19.2 \\
\hline & Tripura & 42.2 & Manipur & 70.6 & Daman and Diu & 0.5 & Goa & 20.8 \\
\hline & Meghalaya & 32.3 & Nagaland & 69.4 & Himachal Pradesh & 0.5 & Chandigarh & 22.5 \\
\hline & Nagaland & 27.5 & Tripura & 67.8 & Kerala & 0.8 & Lakshadweep & 24.3 \\
\hline
\end{tabular}


Focused CMEs must be planned in states and regions with a high prevalence of drug addiction. The 2017 ICP guidelines can be used as a springboard to further discussion and research. At the same time, the drug de-addiction fraternity should be made aware of the need to focus on metabolic health in persons with addictive disorders. This can be best achieved by collaboration between both fields of medicine.

By highlighting recent epidemiological data, and current guidelines from India, we hope to promote health care for both DM and addictive disorders.

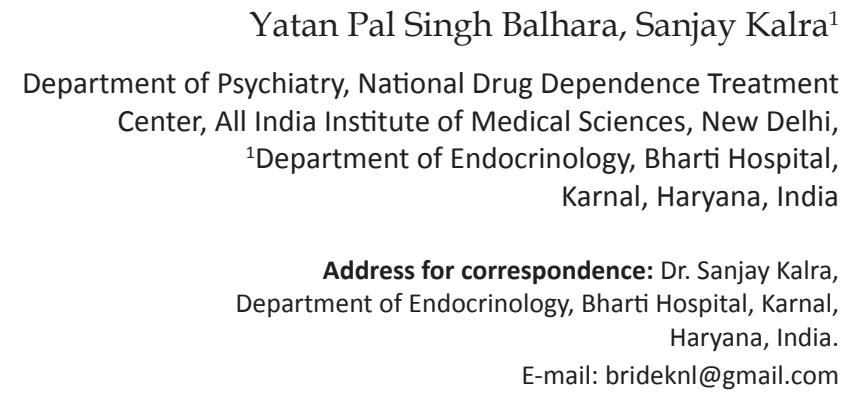

\section{REFERENCES}

1. Balhara YPS, Kalra S, Pattnaik KP, Kallaiselvan V, Unnikrishnan AG, Tiwaskar M, et al. Indian College of Physicians Position statement: Addictive Disorders among persons with Diabetes Mellitus. Accepted for publication in JAPI.

2. Patnaik PK, Jain KK, Chandra P, Pathak J, Raman KV, Shah A. Diabetes in India: Measuring the dynamics of a public health catastrophe. J Soc Health Diabetes 2016;4:77.

3. Charlson FJ, Baxter AJ, Cheng HG, Shidhaye R, Whiteford HA. The burden of mental, neurological, and substance use disorders in China and India: A systematic analysis of community representative epidemiological studies. Lancet 2016;388:376-89.

4. NFHS-4 Fact Sheets for Key Indicators Based on Final Data. Available from: http://rchiips.org/NFHS/factsheet_NFHS-4.shtml. [Last accessed on 2017 Apr 01].

5. Madhu SV, Saboo B, Makkar BM, Reddy GC, Jana J, Panda JK, et al. RSSDI clinical practice recommendations for management of type 2 diabetes mellitus, 2015. Int J Diabetes Dev Ctries 2015;35:1-71.

6. Kalra S, Bajaj S, Das AK. Indian Research Society for the study of Diabetes in India (RSSDI) recommendations for diabetes management: A psychosocial commentary. J Soc Health Diabetes 2016;4:1.

This is an open access article distributed under the terms of the Creative Commons Attribution-NonCommercial-ShareAlike 3.0 License, which allows others to remix, tweak, and build upon the work non-commercially, as long as the author is credited and the new creations are licensed under the identical terms.

\begin{tabular}{|l|l|}
\hline \multicolumn{2}{|c|}{ Access this article online } \\
\hline Quick Response Code: & Website: \\
\hline & www.joshd.net \\
\cline { 2 - 2 } & DOI: \\
\hline & 10.4103/joshd.J_Soc_Health_ \\
\hline
\end{tabular}

How to cite this article: Balhara YP, Kalra S. The alcohol and tobacco burden of India. J Soc Health Diabetes 2017;5:61-2. 